\title{
Influence of bacterial organic selenium on blood parameters, immune response, selenium retention and intestinal morphology of broiler chickens
}

\author{
A. M. Dalia ${ }^{1,2}$, T. C. Loh ${ }^{1}$, A. Q. Sazili ${ }^{1}$ and A. A. Samsudin ${ }^{1 *}$
}

\begin{abstract}
Background: Several studies indicated that dietary organic selenium (Se) usually absorbed better than an inorganic source, with high retention and bioavailability. Dietary Se as an antioxidant element affects the immune system and hematological status in animals. Therefore, the aim of this study was to evaluate the effect of dietary supplementation of bacterial selenium as an organic source on hematology, immunity response, selenium retention, and gut morphology in broiler chickens.

Results: The present results revealed that supplementation of inorganic Se was associated with the lowest level of RBC, HB, and PCV with significant difference than ADS18-Se. In the starter stage, both T2 and T5 were associated with the significantly highest IgG level compared to the basal diet, while all supplemented groups showed higher IgM levels compared to the control group. In the finisher phase, all Se supplemented groups showed significant $(P$ < 0.05) increases in IgG, IgA, and IgM levels compared to T1. Birds fed bacterial-Se showed high intestinal villus height and better Se retention more than sodium selenite. The organic selenium of ADS18 had a superior action in improving Se retention compared to ADS1 and ADS2 bacterial Se.

Conclusions: Bacterial organic Se had a beneficial effect on the villus height of small intestine led to high Se absorption and retention. Thus, it caused a better effect of Se on hematological parameters and immunity response.
\end{abstract}

Keywords: bacterial Selenium, retention, immunity, hematology, gut morphology, broiler

\section{Background}

Selenium (Se) is a structural component of at least 25 selenoproteins that contribute in a regulation of various biological functions in the body. Recent studies are converted from focusing on Se toxicity to its essential nutritional effects. A huge number of studies were carried out to evaluate the effects of Se on poultry nutrition and

\footnotetext{
*Correspondence: anjas@upm.edu.my

'Department of Animal Science, Faculty of Agriculture, Universiti Putra Malaysia, 43400 Serdang, Selangor, Malaysia

Full list of author information is available at the end of the article
}

biological functions, and rapid discoveries were made to reveal the proper source of Se and the optimal level that must be added to the poultry diet. Selenium absorption and retention in the body depend mainly on the ingested form [1]. All recent studies demonstrated that organic Se is more bioavailable than inorganic forms in poultry nutrition [2,3]. Organic Se is usually associated with higher absorption and retention compared to the inorganic form [4]. Moreover, organic Se is retained in the muscle tissues more than inorganic Se due to their different absorption pathways. Organic Se retained in a 
higher level in spleen, duodenum and ileum, indicating higher Se absorption, while lower Se concentrations were found in the brain, liver, and breast [5]. Organic Se of the yeast origin showed greater Se levels in liver and breast tissues compared to birds fed elemental Se, sodium selenite and the basal diet [6]. In the study of Zhao et al., [7] organic selenium compound called 2-hydroxy4-methylselenobutanoic acid $(\mathrm{SeO})$ showed a unique ability to enrich selenomethionine and total selenium depositions more than sodium selenite and selenium yeast. Which induce the early expression of some selenoproteins and to enhance the protein production of GPX4 in the tissues of chicks. According to Rajashree, et al. [8], organic Se at the level of $0.5 \mathrm{ppm}$ showed high Se retention compared to inorganic form in broiler chickens.

Improvement of Se retention usually associated with better selenoprotein synthesis and efficient biological functions such as immunity response and blood formation. Selenium supplementation in different sources significantly improved white blood cells (WBCs) and red blood cells (RBCs) in broiler chickens compared to sodium selenite. However among the different Se sources, elemental Se had the better effect on the immunity response [9]. Moreover, it has been reported that Se deficient diets lead to a cellular and humoral immunity damages. The benefits of selenium supplementation are to boost selenoprotein expression and immunity response and offer a more precise approach for moderating chronic inflammation [10]. Nutritional supplementation of organic selenium plays a vital role in the activity of multiple components of the animal's immune system [11].
Recently Tong et al. [12], revealed that seleniumenriched yeast can reduce induced intestinal injury in broiler chickens with significant increases in the body weight, feed conversion ratio, villi height, and villus/crypt ratio. But rare studies have been conducted to compare the effect of organic and inorganic selenium on intestinal morphology and selenium retention. Therefore, the current study sought to examine the impact of various organic bacterial selenium sources compared to the inorganic form on hematology, immunity response, selenium retention, and gut morphology in broiler chickens.

\section{Results}

\section{Hematological parameters}

The effects of inorganic and bacterial organic Se on the whole blood parameters of 42-day-old broilers are shown in Table 1. There was significant reduction of $\mathrm{RBC}, \mathrm{Hb}$ and PCV in birds supplemented with inorganic Se (T2), whereas an increase in organic fed group particularly ADS18. However, the distinct was between inorganic (T2) and organic (T5) Se supplemented birds. Moreover, T2, T3, and T5 showed significant reduction $(P<0.05)$ in WBC compared to the basal diet, while, no significant difference was observed between $\mathrm{T} 1$ and $\mathrm{T} 4$. The remaining hematological parameters were unaffected by the treatment's effects.

\section{Plasma immunoglobulins}

The effects of inorganic and bacterial organic Se on plasma IgG, IgA, and IgM concentration are shown in Table 2. The dietary Se supplementation resulted to significant differences $(P<0.05)$ of IgG and IgA in the

Table 1 Effect of inorganic and bacterial organic selenium on serum hematological parameters in broiler chickens

\begin{tabular}{|c|c|c|c|c|c|c|c|c|}
\hline \multicolumn{9}{|c|}{ Dietary Treatments $^{1}$} \\
\hline Parameters & T1 & T2 & T3 & T4 & T5 & SEM & $P$ & Ref \\
\hline$\overline{\mathrm{RBC}} \times 10^{12} / \mathrm{L}$ & $2.47^{a b}$ & $2.25^{b}$ & $2.47^{\mathrm{ab}}$ & $2.47^{\mathrm{ab}}$ & $2.64^{a}$ & 0.05 & 0.037 & $1.82-3.46$ \\
\hline $\mathrm{HB} \mathrm{g} / \mathrm{L}$ & $114.3^{a b}$ & $106.6^{b}$ & $117.5^{\mathrm{ab}}$ & $118.0^{a b}$ & $125.5^{\mathrm{a}}$ & 2.1 & 0.011 & 79-159 \\
\hline PCV L/L & $0.277^{a b}$ & $0.258^{b}$ & $0.282^{a b}$ & $0.280^{a b}$ & $0.300^{\mathrm{a}}$ & 0.01 & 0.025 & $0.25-048$ \\
\hline $\mathrm{MCV} \mathrm{FI}$ & 112.8 & 115.0 & 114.0 & 113.3 & 113.5 & 0.75 & 0.912 & $100-200$ \\
\hline $\mathrm{MCHC} \mathrm{g} / \mathrm{L}$ & 411.5 & 413.5 & 416.3 & 421.7 & 419.0 & 2.68 & 0.820 & $376-456$ \\
\hline $\mathrm{WBC} \times 10^{9} / \mathrm{L}$ & $39.5^{\mathrm{a}}$ & $28.2^{b c}$ & $21.4^{c}$ & $37.3^{a b}$ & $18.7^{c}$ & 2.73 & 0.006 & $13.84-37.82$ \\
\hline Hetro $\times 10^{9} / \mathrm{L}$ & 23.8 & 18.8 & 12.4 & 21.6 & 12.2 & 1.78 & 0.128 & $1.68-25.42$ \\
\hline Lymp \% & 18.8 & 21.5 & 27.0 & 25.3 & 18.5 & 1.36 & 0.170 & $12.34-32.78$ \\
\hline Mono \% & 8.3 & 6.0 & 7.5 & 7.0 & 5.5 & 0.66 & 0.768 & $2.52-12.3$ \\
\hline Eosin \% & 2.8 & 2.5 & 3.0 & 3.7 & 3.0 & 0.28 & 0.797 & $2.06-3.89$ \\
\hline Baso\% & 8.5 & 3.8 & 5.0 & 6.7 & 7.5 & 0.93 & 0.489 & $4.67-9.86$ \\
\hline Thrombo $\times 10^{9} / \mathrm{L}$ & 9.1 & 2.4 & 2.6 & 1.1 & 1.8 & 0.3 & 0.277 & $0.95-11.82$ \\
\hline
\end{tabular}

${ }^{1} \mathrm{~T} 1$; basal diet, T2; basal diet + $0.3 \mathrm{mg} / \mathrm{kg}$ feed sodium selenite, T3; basal diet + $0.3 \mathrm{mg} / \mathrm{kg}$ feed ADS1 Se, T4; basal diet + $0.3 \mathrm{mg} / \mathrm{kg}$ feed ADS2 Se, T5; basal diet $+0.3 \mathrm{mg} / \mathrm{kg}$ feed ADS18 Se

a,b,c Means in the same row with different superscripts are significantly different. Ref; refrence values according to Haematology \& Clinical Biochemistry Laboratory, Faculty of Vetrinary Medicine. UPM 
Table 2 Effects of inorganic selenium and different sources of bacterial organic selenium on plasma immunoglobulin levels in broiler chickens

\begin{tabular}{|c|c|c|c|c|c|c|c|c|}
\hline \multicolumn{9}{|c|}{ Dietary Treatments $^{1}$} \\
\hline Parameters & T1 & & T2 & T3 & $\mathrm{T} 4$ & T5 & SEM & $P$-value \\
\hline \multicolumn{9}{|l|}{ DAY 21} \\
\hline $\operatorname{lgG}(\mathrm{mg} / \mathrm{mL})$ & & $133.1^{\mathrm{b}}$ & $364.6^{\mathrm{a}}$ & $298.5^{\mathrm{ab}}$ & $298.7^{\mathrm{ab}}$ & $372.0^{\mathrm{a}}$ & 33.38 & 0.032 \\
\hline $\lg A(u g / m L)$ & & $763.8^{b}$ & $743.0^{\mathrm{b}}$ & $1335.7^{\mathrm{a}}$ & $754.8^{b}$ & $1085.2^{\mathrm{ab}}$ & 70.78 & 0.022 \\
\hline $\lg M(\mathrm{ug} / \mathrm{mL})$ & & $481.6^{c}$ & $552.2^{\mathrm{ab}}$ & $502.7^{b}$ & $608.4^{a}$ & $508.5^{b}$ & 37.13 & 0.041 \\
\hline \multicolumn{9}{|l|}{ DAY 42} \\
\hline $\operatorname{lgG}(\mathrm{mg} / \mathrm{mL})$ & & $258.4^{b}$ & $469.0^{\mathrm{a}}$ & $454.4^{\mathrm{a}}$ & $450.1^{\mathrm{a}}$ & $476.4^{a}$ & 25.66 & 0.045 \\
\hline $\lg A(u g / m L)$ & & $1156.9^{b}$ & $1294.5^{a}$ & $1202.4^{\mathrm{a}}$ & $1193.4^{\mathrm{a}}$ & $1117.6^{\mathrm{a}}$ & 75.01 & 0.014 \\
\hline $\operatorname{lgM}(\mathrm{ug} / \mathrm{mL})$ & & $690.5^{b}$ & $840.9^{a}$ & $760.1^{\mathrm{a}}$ & $719.3^{\mathrm{a}}$ & $709.0^{\mathrm{a}}$ & 27.63 & 0.007 \\
\hline
\end{tabular}

${ }^{1} \mathrm{~T} 1$; basal diet, T2; basal diet + $0.3 \mathrm{mg} / \mathrm{kg}$ feed sodium selenite, T3; basal diet + $0.3 \mathrm{mg} / \mathrm{kg}$ feed ADS1 Se, T4; basal diet + $0.3 \mathrm{mg} / \mathrm{kg}$ feed ADS2 Se, T5; basal diet $+0.3 \mathrm{mg} / \mathrm{kg}$ feed ADS $18 \mathrm{Se}$

$a, b, c$ Means in the same column with different superscripts are significantly different

initial (starter) phase of broiler birds. Higher IgG level was observed with birds in T2 and T5, thus, IgA was significantly higher in T3 compared to control (T1) groups, respectively. Neither the inorganic nor the organic Se sources were shown to be better than the other, however they were all better than the control for IgM. A contrary trend was observed in finisher phase. There was significant $(P<0.05)$ increase in IgG, IgA, and IgM among all the Se supplemented groups compared to control, although, no significant differences exist within the Se supplemented groups either.

\section{Selenium retention}

Table 3 shows the Se retention in broiler chickens supplemented with inorganic Se and different sources of bacterial organic selenoprotein for 42 days. Selenium supplemented diets versus basal diet showed a significant difference in ingested and excreted Se compared to the negative control (T1). However, the percentage of Se retention showed a significant difference in the finishing stage with an insignificant effect in the starter stage when the basal diet was contrasted to Se-supplemented diets. Moreover, bacterial organic Se in broiler feed resulted in a significant $(P<0.05)$ increase of finisher ingested Se in contrast to inorganic Se (T2).

In the starter phase, control group was observed to have lower ingested and excreted Se. There was an insignificant difference in the ingested Se among the Se supplemented diets, however, the excreted $\mathrm{Se}$ was significantly $(P<0.05)$ lower in $\mathrm{T} 5$ compared to other dietary groups. Besides that, the retention percentage in this stage was significantly $(P<0.05)$ higher in T5 compared to other treatments. In the finisher diet, ingested Se was significantly different among treatments, which were, 236.3, 705.6, 792.2, 819.9, and 920.4 $\mu \mathrm{g} / \mathrm{g}$ in $\mathrm{T} 1$, T2, T3, T4, and T5, respectively. The excreted Se was

Table 3 Effects of inorganic and bacterial organic Se sources on serum and tissues Se concentration, and selenium retention in broiler chickens

\begin{tabular}{|c|c|c|c|c|c|c|c|c|c|}
\hline \multirow[t]{2}{*}{ Parameters } & \multicolumn{5}{|c|}{ Dietary treatments $^{a}$} & \multirow[t]{2}{*}{ SEM } & \multicolumn{3}{|l|}{$P$ value } \\
\hline & $\mathrm{T1}$ & T2 & T3 & T4 & T5 & & Anova & B & 0 \\
\hline \multicolumn{10}{|l|}{ 0-21 days } \\
\hline Ingested Se $\mu \mathrm{g} / \mathrm{g}$ & $101.05^{b}$ & $403.91^{a}$ & $413.81^{a}$ & $406.80^{a}$ & $407.65^{a}$ & 32.82 & $<0.0001$ & $<0.0001$ & 0.0632 \\
\hline Excreted Se $\mu \mathrm{g} / \mathrm{g}$ & $45.71^{d}$ & $179.95^{\mathrm{ab}}$ & $233.38^{a}$ & $170.57^{b}$ & $109.08^{c}$ & 17.41 & $<0.0001$ & $<0.0001$ & 0.4766 \\
\hline Retention \% & $54.76^{b}$ & $55.45^{b}$ & $46.08^{b}$ & $58.07^{b}$ & $73.24^{a}$ & 2.82 & 0.012 & 0.4694 & 0.4550 \\
\hline \multicolumn{10}{|l|}{ 22-42 days } \\
\hline Ingested Se $\mu \mathrm{g} / \mathrm{g}$ & $236.3^{e}$ & $705.6^{d}$ & $792.2^{c}$ & $819.9^{b}$ & $920.4^{a}$ & 63.95 & $<0.0001$ & $<0.0001$ & $<0.0001$ \\
\hline Excreted Se $\mu \mathrm{g} / \mathrm{g}$ & $118.33^{c}$ & $233.37^{b}$ & $232.75^{b}$ & $302.16^{a}$ & $256.00^{a b}$ & 17.62 & 0.001 & $<0.0001$ & 0.1841 \\
\hline Retention \% & $49.93^{b}$ & $66.93^{a}$ & $70.62^{a}$ & $63.15^{a}$ & $72.19^{a}$ & 2.39 & 0.002 & 0.0002 & 0.6183 \\
\hline
\end{tabular}

$\mathrm{B}=$ basal diet VS Se supplemented diets, $\mathrm{O}=$ organic Se VS inorganic Se, $P<0.05=$ significant differences

a- ${ }^{c}$ Means with different letter within a row differed significantly

${ }^{a}$ T1; basal diet, T2; basal diet + $0.3 \mathrm{mg} / \mathrm{kg}$ feed sodium selenite, T3; basal diet + $0.3 \mathrm{mg} / \mathrm{kg}$ feed ADS1 Se, T4; basal diet + $0.3 \mathrm{mg} / \mathrm{kg}$ feed ADS2 Se, T5; basal diet $+0.3 \mathrm{mg} / \mathrm{kg}$ feed ADS18 Se 
found to be higher in T4 and with lowest in T1. The Se retention percentage remain unchanged among all the Se supplemented diets and significantly $(P<0.05)$ better than the control, this could probably be connected to better body weight recorded in Se treatment groups than in the control group (Fig. 1).

\section{Villus height and crypt depth of the duodenum, jejunum,} and ileum

The villi height and crypt depth of the duodenum, ileum, and jejunum of birds fed inorganic and bacterial organic Se after 21 and 42 days of age are shown in Table 4. At the starter stage, broilers received bacterial organic Se had significantly $(\mathrm{P}<0.05)$ higher duodenum, ileum, and jejunum villi height compared to those fed the basal diet. Supplementation of bacterial organic Se showed higher jejunum villi height compared to inorganic Se (T2), also in the duodenum villi height, T4 and T5 of bacterial organic Se were significantly $(\mathrm{P}<0.05)$ higher than $\mathrm{T} 2$. On the other hand, no significant difference was observed in the ileum villi height between the birds fed inorganic and bacterial organic Se except in T3 of bacterial organic Se, which indicated lower villi height compared to T2. Furthermore, no significant differences were observed for crypt depth in duodenum, jejunum, and ileum among all the treatments groups.

At the finisher phase, birds fed diet T4 and T5 had significantly $(\mathrm{P}<0.05)$ higher villus height in the duodenum than the inorganic Se (T2) and the basal diet (T1), respectively. There were no significant differences $(\mathrm{P}>$ 0.05) among T1, T2, and T3 treatments for the duodenal villus height. Moreover, there were no significant differences for villi height in the ileum and jejunum among the all treatment group. The experimental diets had no effects on the duodenum, jejunum, and ileum crypt depth.

\section{Discussion}

Hematological indices are good indicators of the animals' physiological status and have a positive correlation with the animals' nutritional status [13]. Selenium deficiency is associated with high generation of reactive oxygen species and exposure of erythrocytes to high degrees of oxidative stress [14]. Glutathione peroxidase is an enzyme that plays a major role in protection of erythrocytes and hemoglobin in erythrocytes against free radicals and oxidative stress. This enzyme contains selenium and therefore selenium is indirectly involved in the prevention of oxidative damage to erythrocytes [15]. Results obtained by Okunlola et al. [16], demonstrated that Se supplementation in different levels had no effect on PCV, HB, RBC and, WBC, whereas, significant differences $(P<0.05)$ was reported in heterophyl and lymphocytes. According to Chen et al. [3] and Boostani et al. [17], different selenium sources had no effect on blood WBC, RBC, HB, and PLT of broiler chickens. In contrast, Biswas et al. [18] and Fawzy et al. [19], reported that Se supplementation increased the erythrocytes counts in poultry and changed PCV and HB significantly, and this supports the finding of this study that, supplementation of bacterial organic Se of (T5), showed significantly higher level of $\mathrm{RBC}, \mathrm{HB}$, and PCV compared to sodium selenite. Also, the finding of the current

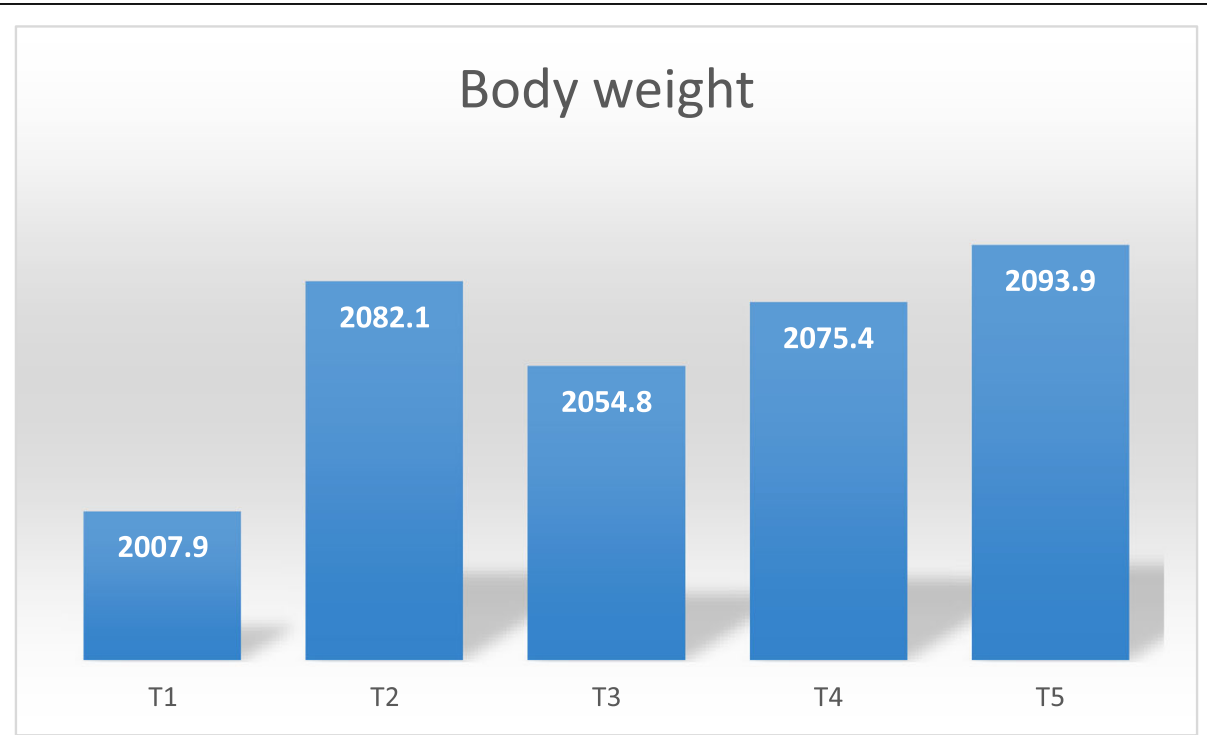

Fig. 1 Forty-two-days body weight of broiler chicken. Treatments: T1; basal diet, T2 basal diet $+0.3 \mathrm{mg} / \mathrm{kg}$ sodium selenite, T3: basal diet +0.3 $\mathrm{mg} / \mathrm{kg}$ Se of ADS1, T4; basal diet $+0.3 \mathrm{mg} / \mathrm{kg}$ Se of ADS2, T5: basal diet + $0.3 \mathrm{mg} / \mathrm{kg}$ Se of ADS18. Bars with no common letter differ significantly $(P<0.05)$ 
Table 4 Effects of inorganic and bacterial organic selenium sources on villus height and crypt depth of the duodenum, jejunum, and ileum in broiler chickens

\begin{tabular}{|c|c|c|c|c|c|c|c|}
\hline \multirow[t]{2}{*}{ Parameters } & \multicolumn{5}{|c|}{ Dietary treatments ${ }^{1}$} & \multirow[b]{2}{*}{ SEM } & \multirow[b]{2}{*}{$P$-value } \\
\hline & $\mathrm{T} 1$ & $\mathrm{~T} 2$ & T3 & T4 & T5 & & \\
\hline \multicolumn{8}{|l|}{21 days } \\
\hline \multicolumn{8}{|c|}{ Villi height $\mu \mathrm{m}$} \\
\hline Duodenum & $914.0^{c}$ & $930.9^{\mathrm{cb}}$ & $1020.5^{\mathrm{ab}}$ & $1109.6^{a}$ & $1141.9^{a}$ & 20.72 & $<0.0001$ \\
\hline Jejunum & $458.23^{b}$ & $514.12^{b}$ & $599.33^{a}$ & $622.76^{\mathrm{a}}$ & $593.07^{a}$ & 14.63 & 0.0002 \\
\hline Ileum & $326.53^{c}$ & $484.97^{\mathrm{a}}$ & $402.35^{b}$ & $430.14^{\mathrm{ab}}$ & $475.16^{\mathrm{a}}$ & 13.18 & $<0.0001$ \\
\hline \multicolumn{8}{|c|}{ Crypt depth, $\mu \mathrm{m}$} \\
\hline Duodenum & 80.87 & 75.15 & 78.35 & 74.17 & 73.88 & 1.82 & 0.7199 \\
\hline Jejunum & 72.07 & 71.63 & 70.75 & 71.83 & 73.21 & 1.51 & 0.9925 \\
\hline Ileum & 75.36 & 75.59 & 70.80 & 72.69 & 71.82 & 2.21 & 0.9508 \\
\hline \multicolumn{8}{|l|}{42 days } \\
\hline \multicolumn{8}{|c|}{ Villi height $\mu \mathrm{m}$} \\
\hline Duodenum & $1159.9^{c}$ & $1163.9^{c}$ & $1155.1^{c}$ & $1200.1^{b}$ & $1265.2^{a}$ & 16.71 & 0.0360 \\
\hline Jejunum & 619.74 & 625.57 & 685.19 & 731.08 & 696.85 & 16.53 & 0.1474 \\
\hline Ileum & 550.62 & 575.92 & 576.10 & 588.88 & 599.52 & 13.92 & 0.8618 \\
\hline \multicolumn{8}{|c|}{ Crypt depth, $\mu \mathrm{m}$} \\
\hline Duodenum & 97.78 & 99.68 & 94.99 & 93.10 & 92.91 & 2.36 & 0.8809 \\
\hline Jejunum & 89.68 & 87.14 & 85.33 & 83.20 & 75.99 & 1.51 & 0.0610 \\
\hline Ileum & 91.61 & 87.75 & 82.81 & 80.99 & 78.81 & 2.38 & 0.4477 \\
\hline
\end{tabular}

${ }^{1} \mathrm{~T} 1$; basal diet, T2; basal diet + $0.3 \mathrm{mg} / \mathrm{kg}$ feed sodium selenite, T3; basal diet + $0.3 \mathrm{mg} / \mathrm{kg}$ feed ADS1 Se, T4; basal diet + $0.3 \mathrm{mg} / \mathrm{kg}$ feed ADS2 Se, T5; basal diet $+0.3 \mathrm{mg} / \mathrm{kg}$ feed ADS18 Se

abc Means with different letter within a row differed significantly

study indicates a significant $(\mathrm{P}>0.05)$ reduction in $\mathrm{WBC}$ in $\mathrm{T} 2, \mathrm{~T} 3$, and $\mathrm{T} 5$ compared to the basal diet, with no significant differences in monocyte, eosinophil and basophil percentages. The present finding is not in agreement with Fawzy et al. [19] and Singh et al. [20] on supplementation of $\mathrm{Se}$ enhances cell mediatedimmunity, and significantly increases WBC. In the present study, the WBC count of Se supplemented treatments was lower than that of the basal diet but still within the reference range according to Mitruka and Rawsley, [21]. In the present study, sodium selenite reduced RBC, PCV, and HB values compared to bacterial organic Se, although all levels are still in the normal range according to Schalm et al. [22] and Mitruka and Rawsley, [21]. The observed reduction of RBC, PCV, and HB due to sodium selenite supplementation, may indicate the high generation of reactive oxygen species of sodium selenite in compare to organic Se. Sodium selenite can produce free radicals which adversely affects the blood formation through denaturation of hemoglobin, and causes of hemolysis that reduced life-span of circulating erythrocytes [23]. On the other hand, in rats, dietary sodium selenite for more than one month was associated with decreases in RBC, PCV, WBC, and $\mathrm{HB}$ levels [24]. Also, repeated selenite treatment may reduce hemoglobin synthesis and induce a condition of hypochromic anemia [20], this may be attributed to the potential production of reactive oxygen species associated with chronic selenite supplementation. Dietary selenium supplementation improves lymphocyte divisions which is followed by a better immune response. Moreover, Se supplementation exerts its effects on immunity response mostly through its incorporation into selenoproteins such as glutathione peroxidases (GPXs), thioredoxin reductases (TXNRDs), iodothyronine deiodinases (DIOs), and selenophosphate synthetase 2 (SPS2). For nonenzymatic selenoproteins, the best characterized in terms of immune cell function is selenoprotein K (SELE NOK) [10]. In the current study, both inorganic Se and bacterial organic Se of (ADS18) showed a significant increase in IgG concentration in the starter phase compared to the basal diet, but a bacterial organic Se of (ADS1) and of (ADS2) showed the highest IgA and IgM levels respectively, compared to other treatments. In the finisher stage dietary Se raised both IgG, IgA, and IgM concentrations with no significant difference between inorganic and bacterial organic Se. These data are in line with $\mathrm{Lu}$ et al. [25], who reported that Se-enriched exopolysaccharides (Se-ECZ-EPS) produced by Enterobacter cloacae Z0206 showed a significant increase in serum 
antibody titers against Newcastle disease virus in birds treated with $840 \mathrm{mg} / \mathrm{kg}$ Se-ECZ-EPS. They also partially agree with the finding that supplementation of different nano- Se levels in broiler chickens had no effect on the serum IgG, IgM, and IgA of the starter phase, while the birds supplemented $0.3 \mathrm{mg} / \mathrm{kg}$ of nano-Se showed the highest IgG and IgM levels on day 42 [26]. Also, supplementation with organic and nano-Se resulted in an increasing IgM and IgG concentration compared to the other groups in oxidative and non-oxidative conditions [17]. However, some studies revealed that supplementation of different Se sources (organic and inorganic) did not affect immunoglobulins IgG, IgA, and IgM concentrations in the gilt or piglet [27]. Furthermore, Chen et al. [3], stated that both organic and inorganic Se had no effect on serum immunoglobulins at days 21 and 42 . The current finding indicate the role of Se as antioxidant in preventing and maintain more developed B cell lymphocytes, which is lead to more immunoglobins productions [28]. Moreover, Se supplementation induce cytokines secretion from lymphocytes of type $2 \mathrm{~T}$ helper cells (Th2 cells) include Interleukin 4, 5, and 13, which are necessary for starting humoral immunity to specialize B cell lymphocytes for production of immunoglobins [29]. Therefore, dietary Se supplementation played a higher role in promoting humoral immune status in the starter and finisher stages in broiler chickens, but the effect of Se source is no longer observed. In the present study, all birds were vaccinated, which contributed to the dietary component in promoting a greater antigenic stimulation and production of a higher concentration of immunoglobulins. The fluctuation of immunoglobulin concentration observed between the two dietary stages may be attributed to the fact that the antigen that activated the immune response will decline and then most of the $\mathrm{T}$ cells will die, which indicates the feedback mechanism of the immune response.

Generally, organic Se may have better bioavailability and more efficient retention in the body than sodium selenite [30]. Sodium selenite is absorbed less efficiently and excreted at a higher rate compared to organic Se [31]. A study conducted by Yoon et al. [32] to examine the effect of two sources of Se-yeast as an organic Se and sodium selenite in broiler chickens, revealed that organic Se sources were more bioavailable and retained more efficiently than sodium selenite. Also, $\mathrm{Hu}$ et al. [33], indicated that Se retention in the whole body was higher in the group fed nano-Se compared to the group fed sodium selenite. In the current study, broilers fed dietary organic Se of T5, which originated from (ADS18) bacterial strain, retained more $(\mathrm{P}<0.05)$ Se in the body associated with less Se excretion than sodium selenite and other bacterial Se sources at week 3, although, at week 6, they also retained the highest Se level compared to other treatments however, the difference was insignificant. The observed difference compared to the sodium selenite may be due to the fact that sodium selenite having an ability to be bound by mucosal tissues to become unavailable for transfer to the other tissues [34]. Also, because the efficiency of Se from an organic source is related to SeMet content, it could be that organic Se of (ADS18) contains a high amount of SeMet. Therefore, it would be more interesting to investigate the type of Se in each bacterial strain, which could explain why other bacterial strains (ADS1 and ADS2) were not different from sodium selenite.

Measurement of intestinal villus height and crypt depth as morphometric characteristics are important to maintaining normal small intestine for proper absorption of nutrients and preventing translocation of bacteria from the gut [35]. The present results showed that the supplementation of bacterial organic Se had a beneficial effect on villus height in all parts of the small intestine of the starter phase, as well as in the duodenum part of the finisher phase. However, inorganic Se had no effect on the villus height compared to a basal diet except in the starter ileum part. Moreover, both inorganic and bacterial organic Se showed no effect on the crypt depth. This result is partially in line with Zamani-Moghaddam et al. [36], who indicated that supplementation of nanoSe to broiler chickens had a positive influence on villus height in all intestinal parts except the ileum, while the organic Se increased all morphometric parameters in the jejunum part. Ahmed et al. [37], reported that dietary organic Se of Se-yeast had a significant effect on duodenum and jejunum villi height in goat, but did not affect the villus height of ileum. Moreover, a study of ReadSnyder et al. [38], showed that organic Se supplementation in the form of (Sel-Plex) was associated with the greater intestinal villus height compared with the control and sodium selenite-fed birds in both normal and virusinfected groups of broiler. The main function of the small intestine is the digestion and absorption of nutrients. It is well recognised that a shortening of the villi will minimise the surface area for nutrient absorption, and a deeper crypt indicates fast tissue turnover [39]. A shortened villus height and a greater crypt depth are directly correlated with rising enterocyte turnover [40]. On the other hand, dietary antioxidants played a very important role in the enterocytes protection from apoptotic oxidative stress and could improve their development [41]. According to Tong et al. [12], Organic Se in the form of Se- yeast in broiler chickens, increased the intestinal villi height and villus/crypt ratio with significant elevation of an antioxidants and immunity response. Therefore, the improvement in the villus height in the current study may be due to the role of organic Se as an exogenous antioxidant factor, which may positively affect 
enterocytes viability via the active contribution of $\mathrm{Se}$ in intestinal glutathione peroxidase (GSH-Px2).

These findings suggest that bacterial organic Se has the potential role to improve the small intestine villus heights, especially in the duodenum segment which is the main part of Se absorption [42]. The observed differences between organic Se and sodium selenite could be due to the fact that selenite having the ability to be bound by mucosal tissues and thus become unavailable for transfer to the other tissues [34]. These observations suggest that the improved Se retention and assimilation efficiency observed in the birds fed bacterial organic Se particularly (ADS18) can be explained by improved integrity of the intestinal tract and possibly by the improved gut antioxidant status.

\section{Conclusions}

In conclusion, the findings of the current study indicate that selenium is an essential micronutrient in improving the intestinal integrity and immunity response. The supplementation of different sources of bacterial organic Se showed high intestinal villus height and better Se retention more than sodium selenite (inorganic source). Selenium extracted from ADS18 bacterial strain had a superior action in improving Se retention compared to ADS1 and ADS2 bacterial Se. Resulted improvement in
Se retention caused a significant enhancement in blood formation and serum antibodies. Supplementation of bacterial organic Se of ADS18 increased the level of the blood cells, moreover all Se sources increased the immunoglobulins levels compared to the basal diet.

\section{Methods}

\section{Extraction of bacterial selenium content}

fIn the current study, Se enriched bacterial strains identified as Enterobacter cloacae (ADS1), Klebsiella pneumoniae (ADS2), and Stenotrophomonas maltophilia (ADS18) were used as a source of bacterial organic Se. The stock culture of ADS1, ADS2, and ADS18 strains prepared at the Laboratory of Microbiology, Department of Animal Science, Faculty of Agriculture, Universiti Putra Malaysia (UPM) and the sonicated Se-enriched bacterial cells were produced according to the procedure described by Dalia et al. [43]. The extraction of selenoprotein from Se-enriched bacterial cells was carried out using dialysis technique The dialysis process was performed using dialysis sacks of flat width $25 \mathrm{~mm}, 12$, $000 \mathrm{Da}$, (Sigma-Aldrich) against deionised water, which was changed every $12 \mathrm{~h}$ for a total of 96 hours to separate inorganic Se from organic form [44]. The content in the dialysis tube was lyophilised and then used as a source of bacterial Se.

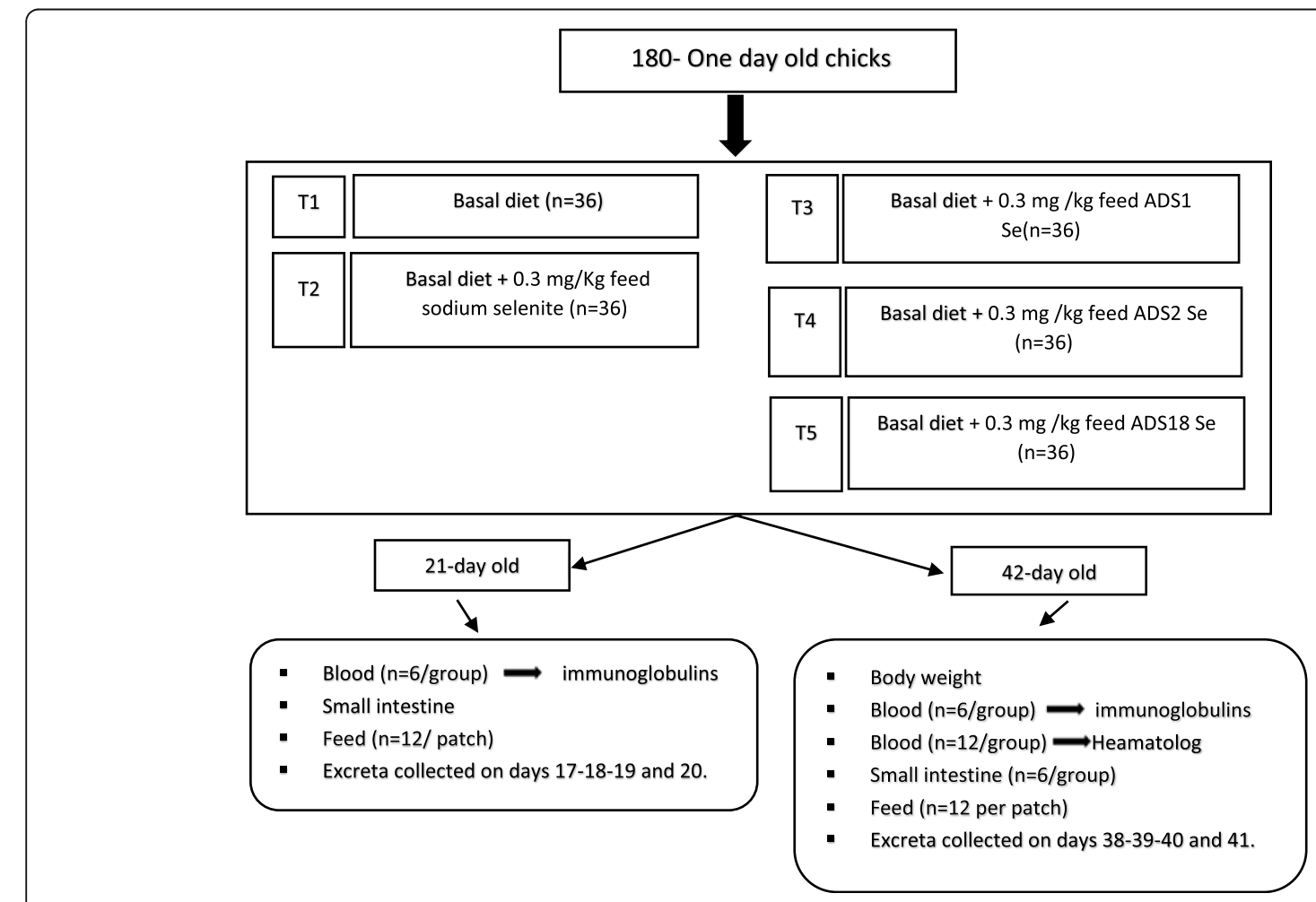

Fig. 2 Schematic diagram of the inorganic and organic selenium feeding trial. $\mathrm{N}$ values present the number of chicks per feeding group or the number of taken samples 


\section{Birds and experimental procedure}

The birds handling and use in this study was carried out in compliance with the research policy guidelines of UPM on Animal Welfare and Ethics. As in (Fig. 2), a total of 180 one-day-old commercials (Cobb 500) female broiler chicks averaging $40 \pm 0.13 \mathrm{~g}$ supplied by a local hatchery were randomly divided into five treatments fed the basal diet (Table 5), each with six replicates of 6 birds per replicate. The dietary treatments consisted of the basal diet supplemented with $(0.3 \mathrm{mg} / \mathrm{kg}$ feed sodium selenite), (0.3 $\mathrm{mg} / \mathrm{kg}$ feed ADS1 Se), $(0.3 \mathrm{mg} / \mathrm{kg}$ feed ADS2 Se), and $(0.3 \mathrm{mg} / \mathrm{kg}$ feed ADS18 Se) in addition to the basal diet treatment served as a control group. Starter diet was offered from 0 to 3 weeks old and finisher from 4 to 6 weeks old. Water and feed were given ad libitum to all the chickens. Experimental birds

Table 5 Ingredients and nutrient content of the basal diet

\begin{tabular}{|c|c|c|}
\hline \multirow[t]{2}{*}{ Ingredients } & Starter & Finisher \\
\hline & $\%$ & $\%$ \\
\hline Corn & 52.5 & 56.250 \\
\hline Palm oil & 5.00 & 6.00 \\
\hline Soybean meal (44\% cp.) & 32.50 & 30.00 \\
\hline Fish meal (58\% cp.) & 5.15 & 3.25 \\
\hline L-Lysine & 0.25 & 0.25 \\
\hline DL-Methionine & 0.25 & 0.25 \\
\hline Dicalcium phosphate $18 \%^{a}$ & 1.60 & 1.85 \\
\hline Calcium carbonate & 0.60 & 0.35 \\
\hline Salt & 0.30 & 0.30 \\
\hline Mineral Premix ${ }^{\mathrm{b}}$ & 0.15 & 0.15 \\
\hline Vitamin Premix ${ }^{c}$ & 0.10 & 0.10 \\
\hline Toxin Binder ${ }^{d}$ & 0.15 & 0.15 \\
\hline Choline Chloride & 0.10 & 0.10 \\
\hline Wheat pollard (QL) & 0.135 & 1.00 \\
\hline \multicolumn{3}{|c|}{ Calculated nutrient content $(\mathrm{g} / \mathrm{kg} \mathrm{DM})^{\mathrm{e}}$} \\
\hline ME (MJ/Kg) & 12.9 & 13.20 \\
\hline Crude protein & 22.04 & 20.09 \\
\hline Crude fat & 7.57 & 8.004 \\
\hline Calcium & 1.189 & 1.0440 \\
\hline Phosphorus & 0.786 & 0.768 \\
\hline Avail. P for Poultry & 0.472 & 0.450 \\
\hline Analyzed Se $(\mathrm{mg} / \mathrm{kg})^{\mathrm{f}}$ & $<0.09$ & $<0.09$ \\
\hline
\end{tabular}

${ }^{a}$ di calcium phosphate provides phosphorus and calcium in a ratio of 1:1 ${ }^{b}$ Mineral premix provided the following per kg diet: iron $120 \mathrm{mg}$, manganese $150 \mathrm{mg}$, copper $15 \mathrm{mg}$, zinc $120 \mathrm{mg}$, iodine $1.5 \mathrm{mg}$, and cobalt $0.4 \mathrm{mg}$ 'Vitamin premix provided the following per kg diet: Vitamin A (retinyl acetate) $10.32 \mathrm{mg}$, cholecalciferol $0.250 \mathrm{mg}$, vitamin E (DL-tocopheryl acetate) $90 \mathrm{mg}$, vitamin K $6 \mathrm{mg}$, cobalamin $0.07 \mathrm{mg}$, thiamine $7 \mathrm{mg}$, riboflavin $22 \mathrm{mg}$, folic acid $3 \mathrm{mg}$, biotin $0.04 \mathrm{mg}$, pantothenic acid $35 \mathrm{mg}$, niacin $120 \mathrm{mg}$ and pyridoxine $12 \mathrm{mg}$

${ }^{\mathrm{d}}$ Toxin binder contains natural hydrated sodium calcium aluminium silicates f The Se content measured using ICP.MS

${ }^{\mathrm{e}}$ The diets were formulated using feedlive International software (Thailand) were housed in UPM- farm (Ladang-2) using the semiclosed system. Lightening was $12 \mathrm{~h}$ per day. All the birds subjected to vaccination against bronchitis (IB) and Newcastle disease (ND) on day 7, and against infectious bursal disease on day 14 through the intraocular route.

\section{Hematological parameters}

On completion of the experiment, twelve birds from each dietary treatment (2 birds from each replicate) were selected at random, then weighted and sacrificed. The slaughter procedure was conducted at the Department of Animal Science slaughterhouse, Faculty of Agriculture, Universiti Putra Malaysia. The animals were humanely slaughtered by a licensed slaughter man. The procedure involved severing the carotid artery, jugular vein, trachea and esophagus. Blood samples were taken directly from the neck vein into a vacuum tube (BD Vacutainer, NJ. USA) containing an anticoagulant (EDTA) and directed to hematological analysis using hematology analyzer (CELL DYN 3700, Abbott USA).

\section{Plasma immunoglobulin concentration}

At days 21 and 42, 6 birds per treatment were randomly selected and blood samples were collected into vacutainer tubes containing ethylene diamine tetra acetic acid (EDTA). Blood samples were mixed gently before storage in ice, followed by centrifuging at $3000 \mathrm{rpm}$ for 15 min at $4{ }^{\circ} \mathrm{C}$, and the plasma was stored at $-80{ }^{\circ} \mathrm{C}$ until antibody analysis.

Plasma IgA and IgM were determined using (Chicken IgA ELISA, Immunology Consultants Laboratory, Inc. USA) and (Chicken IgM ELISA, Immunology Consultants Laboratory, Inc., USA), while Chicken IgG determined using (CEA544Ga, Enzyme-linked Immunosorbent Assay Kit, Cloud-Clone Corp., USA). All the analysis performed according to the procedure recommended by the manufacturer. The absorbance was measured at $450 \mathrm{~nm}$ wavelength using a micro-plate reader (Infinite $200 \mathrm{PRO}, \mathrm{TECAN}$ ).

\section{Selenium retention}

Twelve representative samples from each batch of feed (starter and finisher diets) were collected randomly and kept at $-20{ }^{\circ} \mathrm{C}$ until further analysis. Total excreta collection was performed on days $17,18,19$, and 20 for a starter diet and on days 38, 39, 40, 41 for finisher diet. Feed and fecal samples were analyzed for Se concentration using ICP.MS. Determination of Se retention was calculated using a mass balance method [45] as follows:

Se retention $(\%)=($ Ingested Se - Excreted Se $) \times 100$.

\section{Ingested Se}

Ingested $\mathrm{Se}=$ daily feed intake $\times$ analytical feed $\mathrm{Se}$ concentration.

Excreted Se $=$ daily feces weight $\times$ feces Se concentration. 


\section{Histomorphology of small intestine}

Intestinal morphology was done employing the method stated by Choe et al. [46]. The intestinal samples of 6 birds/ treatment were collected at days 21 and day 42 . Approximately $5 \mathrm{~cm}$ segments of the ileum (midway between the Meckel's diverticulum and ileo-caecal junction), a middle portion of the duodenum (apex section), and jejunum (midway between the endpoint of the duodenal loop and Meckel's diverticulum) were cut gently and washed with phosphate buffer saline (PBS) and fixed in $10 \%$ neutral buffered formalin. Then, the intestinal samples were dried for $16 \mathrm{~h}$ in an automatic tissue processor (Leica ASP 3000, Tokyo, Japan) and embedded in paraffin wax following a paraffin embedding system (Leica EG 1160, Japan). Each sample was cut at $4 \mu \mathrm{m}$ with a rotary microtome machine (Leica RM 2155, Japan). Sections of size $4 \mathrm{~mm}$ were fixed on glass slides, heated at $57 \mathrm{oC}$ until dried, and stained with hematoxylin and eosin. The distance from the tip of the villi to the villus crypt junction represented the villus height, while, crypt depth was described as the depth of the invagination between 2 villi and was determined to employ Image-Pro Plus software as described by Touchette et al. [47]. A total of 5 villi sections per slide were evaluated in each of 6 replicate slides per intestinal sample (30 measurements for each sample) and studied with a light microscope (Dialux, LeitzWetzlar, Germany) fitted with a digital camera (Laice, Germany).

\section{Statistical analysis}

Data were analyzed using one-way analyses of variance (ANOVA) using the Proc GLM procedure of SAS software (SAS Institute Inc., Cary, NC). The assumption of normality was by using the visual assessment of histogram distribution and Quantile-Quantile (Q-Q) plots of model residual. Duncan Multiple Range Test was used for comparisons of means for each significant difference among the treatment groups at a significant level $(P<$ 0.05). The F test was also performed to determine the orthogonal contrasts among treatments.

(1) Basal diet vs. Se supplemented diets,

(2) Sodium selenite vs. bacterial organic Se,

Values of $P<0.05$ were accepted as significant.

\begin{abstract}
Abbreviations
Se: Selenium; ADS1: Enterobacter cloacae; ADS2: Klebsiella pneumonia; ADS18: Stenotrophomonas maltophilia; RBCs: Red blood cells; HB: Hemoglobin; PCV: Packed cell volume; IgA: Immunoglobulin A; IgG: Immunoglobulin G; IgM: Immunoglobulin M
\end{abstract}

\section{Acknowledgements}

Not Applicable.

\section{Authors' contributions}

D.A.M., A.A.S., L.T.C. and S.A.Q contributed to the original idea and design of the study. D.A.M. conducted the experiments and collected the data. All authors were involved in the manuscript preparation and approved the final manuscript.

\section{Funding}

This study was financed by the Fundamental Research Grant Scheme (FRGS 5524272) granted by Malaysian Ministry of Higher Education. The funder had no role in the design of the study, collection, analysis and interpretation of the data or in writing the manuscript. D.A.M. was a recipient of scholarship from the Ministry of Higher Education and Scientific Research of Sudan and University of Khartoum, Sudan.

\section{Availability of data and materials}

The datasets used and/or analysed during the current study are available from the corresponding author on reasonable request.

\section{Ethics approval and consent to participate}

It is confirmed that Institutional Animal Care and Use Committee (IACUC), Universiti Putra Malaysia approved this study.

\section{Consent for publication}

Not applicable

\section{Competing interests}

The authors declare that they have no competing interests.

\section{Author details}

${ }^{1}$ Department of Animal Science, Faculty of Agriculture, Universiti Putra Malaysia, 43400 Serdang, Selangor, Malaysia. ²Department of Animal Nutrition, Faculty of Animal Production, University of Khartoum, Khartoum, Sudan.

Received: 6 January 2020 Accepted: 22 September 2020

Published online: 29 September 2020

\section{References}

1. Payne RL, Southern LL. Comparison of inorganic and organic selenium sources for broilers. Poult Sci. 2005;84(6):898-902.

2. Hassan FA, Abdel-Azeem NM, Abdel-Rahman SM, Amin HF, Abdel-Mawla LF. Effect of Dietary Organic Selenium Supplementation on Growth Performance, Carcass Characteristics and Antioxidative Status of Growing Rabbits. World. 2019:9(1):16-25.

3. Chen $\mathrm{G}, \mathrm{Wu}$ J, Li C. Effect of different selenium sources on production performance and biochemical parameters of broilers. J Anim Physiol Anim Nutr. 2014. doi:https://doi.org/10.1111/jpn.12136.

4. Marsh JA, Dietert RR, Combs GF Jr. Influence of dietary selenium and vitamin $\mathrm{E}$ on the humoral immune response of the chick. Proc Soc Exp Biol Med. 1981;166(2):228-36.

5. Sheeana G, Ivan D, Nicky-Lee W, Robert JM, James C, Dragana S. Nanoparticles of selenium as high bioavailable and non-toxic supplement alternatives for broiler chickens. Environ Sci Pollut Res Int. 2020. doi:https:// doi.org/10.1007/s11356-020-07962-7.

6. Woods SL, Sobolewska S, Rose SP, Whiting IM, Blanchard A, lonescu C, et al. Effect of feeding different sources of selenium on growth performance and antioxidant status of broilers. Br Poult Sci. 2020;7:1-7.

7. Zhao L, Sun LH, Huang JQ, Briens M, Qi DS, Xu SW, et al. A novel organic selenium compound exerts unique regulation of selenium speciation, selenogenome, and selenoproteins in broiler chicks. J Nutr. 2017;147(5):78997.

8. Rajashree K, Muthukumar T, Karthikeyan N. Influence of inorganic and organic selenium sources on broiler performance and meat quality. Iran J Appl Anim Sci. 2014;151-157.

9. Shabani R, Fakhraei J, Yarahmadi HM, Seidavi A. Effect of different sources of selenium on performance and characteristics of immune system of broiler chickens. Rev Bras Zootec. 2019. https://doi.org/10.1590/rbz4820180256.

10. Avery JC, Hoffmann PR. Selenium, selenoproteins, and immunity. Nutr. 2018; 10(9):1203.

11. Oliveira TFB, Rivera DFR, Mesquita FR, Braga $H$, Ramos EM, Bertechini AG. Effect of different sources and levels of selenium on;performance, meat quality, and tissue characteristics of broilers. JAppl Poult Res. 2014. https:// doi.org/10.3382/japr.2013-00761. 
12. Tong C, Peng L, Li-Hui $Y$, Lin L, Kang L, Yueli $C$, et al. Selenium-rich yeast attenuates ochratoxin A-induced small intestinal injury in broiler chickens by activating the Nrf2 pathway and inhibiting NF-KB activation. J Funct Foods. 2020. https://doi.org/10.1016/j.jff.2020.103784.

13. Adejumo DO. Performance, organ development and hematological indices of rats fed sole diets of graded levels of cassava flour and soybean flour (soygari) as substitutes for energy and protein concentrates. Trop J Anim Sci. 2004:7:57-63.

14. Zheng S, Zhao J, Xing H, Xu S. Oxidative stress, inflammation, and glycometabolism disorder-induced erythrocyte hemolysis in seleniumdeficient exudative diathesis broilers. J Cell Physiol. 2019;234(9):16328-37.

15. Huang Z, Rose AH, Hoffmann PR. The role of selenium in inflammation and immunity: from molecular mechanisms to therapeutic opportunities. Antioxid Redox Sign. 2012;16(7):705-43.

16. Okunlola D, Akande TO, Nuga H. Haematological and serum characteristics of broiler birds fed diets supplemented with varying levels of selenium powder. J Biol Agric Healthc. 2015;5(1):107-11.

17. Boostani A, Sadeghi AA, Mousavi SN, Chamani M, Kashan N. Effects of organic, inorganic, and nano-Se on growth performance, antioxidant capacity, cellular and humoral immune responses in broiler chickens exposed to oxidative stress. Livest Sci. 2015;178:330-6.

18. Biswas A, Ahmed M, Bharti VK, Singh SB. Effect of antioxidants on physiobiochemical and hematological parameters in broiler chicken at high altitude. Asian-Austral J Anim Sci. 2011;24(2):246-9.

19. Fawzy MM, El-sadawi HA, El-dien MH. Hematological and biochemical performance of poultry following zinc oxide and sodium selenite supplementation as food additives. Ann Clin Pathol. 2016:4(4):1076.

20. Singh VP, Sahu DS, Singh MK, Manoj J. Effect of supplementation of Selenium and Ashwagandha (Withania somnifera) on some haematological and immunological parameters of broiler chickens. Scholars J Agric Vet Sci. 2016. doi:https://doi.org/10.21276/sjavs.2016.3.6.2

21. Mitruka B, Rawsley H. Clinical biochemical and hematological reference values in normal experimental animals. 2nd ed. U.S.A: Masson Publishing; 1981.

22. Schalm O, Jain N, Carol E. Veterinary haematology. 3rd ed. Philadelphia: Lea and Febiger; 1975

23. Jia X, Li N, Chen J. A subchronic toxicity study of elemental Nano-Se in Sprague-Dawley rats. Life Sci. 2005;76(17):1989-2003.

24. Hogan GR, Jackson PD. Dichotomous effects of cadmium and selenium on erythropoiesis in mice. B Environ Contam Tox. 1986:36(1):674-9.

25. Lu Z, Jin M, Huang M, Wang Y, Wang Y. Bioactivity of selenium-enriched exopolysaccharides produced by Enterobacter cloacae Z0206 in broilers. Carbohydr Polym. 2013. doi:https://doi.org/10.1016/j.carbpol.2013.03.063.

26. Cai SJ, Wu CX, Gong LM, Song T, Wu H, Zhang LY. Effects of nano-selenium on performance, meat quality, immune function, oxidation resistance, and tissue selenium content in broilers. Poult Sci. 2012;91:2532-9.

27. Gelderman A, Clapper J. Effects of inorganic or organic selenium on immunoglobulins in swine. J Anim Sci Biotechnol. 2013. doi:https://doi.org/ 10.1186/2049-1891-4-47.

28. Yang N, Larsen CT, Dunnington TE, Geraert PA, Picard PM, Siegel PB. Immune competence of chicks from two lines divergently selected for antibody response to sheep red blood cells as affected by supplemental vitamin E. Poult Sci. 2000. https://doi.org/10.1093/ps/79.6.799.

29. Abbas AK, Lichtman AH, Pillai S. Cellular molecular immunology. 8th ed. Philadelphia: Elsevier; 2015

30. Schrauzer GN. Selenomethionine: a review of its nutritional significance, metabolism and toxicity. J Nutr. 2000;130(7):1653-6.

31. Mahan DC, Parrett NA. Evaluating the efficacy of selenium-enriched yeast and sodium selenite on tissue selenium retention and serum glutathione peroxidase activity in grower and finisher swine. J Anim Sci. 1996;74(12): 2967-74.

32. Yoon I, Werner TM, Butler JM. Effect of source and concentration of selenium on growth performance and selenium retention in broiler chickens. Poult Sci. 2007:86:727-30.

33. Hu CH, Li YL, Xiong L, Zhang HM, Song J, Xia MS. Comparative effects of nano elemental selenium and sodium selenite on selenium retention in broiler chickens. Anim Feed Sci Technol. 2012;177(3-4):204-10.

34. Mykkanen $\mathrm{H}$, Wasserman R. Uptake of 75Se-selenite by brush border membrane vesicles from chick duodenum stimulated by vitamin D. J Nutr 1989:119(2):242-7.
35. Quinteiro-Filho WM, Ribeiro A, Ferraz-De-Paula V, Pinheiro ML, Sakai M, Sá LRM, et al. Heat stress impairs performance parameters, induces intestinal injury, and decreases macrophage activity in broiler chickens. Poult Sci. 2010. doi:https://doi.org/10.3382/ps.2010-00812.

36. Zamani-Moghaddam AK, Mehraei-Hamzekolaei MH, Khajali F, Hassanpour H. Role of selenium from different sources in prevention of pulmonary arterial hypertension syndrome in broiler chickens. Biol Trace Elem Res. 2017. doi: https://doi.org/10.1007/s12011-017-0993-3.

37. Ahmed Z, Malhi M, Soomro SA, Gandahi JA, Arijo A, Bhutto B, et al. Dietary selenium yeast supplementation improved some villi morphological characteristics in duodenum and jejunum of young goats. J Anim Plant Sci. 2016;26(2):382-7.

38. Read-Snyder J, Edens FW, Cantor AH, Pescatore AJ, Pierce JL. Effect of dietary selenium on small intestine villus integrity in reovirus-challenged broilers. Int J Poult Sci. 2009:8(9):829-35.

39. Zhang W, Lee BD, Lee SK, Lee KW, An GH, Song KB, et al. Effects of yeast (Saccharomyces cerevisiae) cell components on growth performance, meat quality, and ileal mucosa development of broiler chicks. Poult Sci. 2005; 84(7):1015-21.

40. Fan YK, Croom J, Christensen VL, Black BL, Bird AR. Jejunal glucose uptake and oxygen consumption in turkey poults selected for rapid growth. Poult Sci. 1997:76(12):1738-45.

41. Ahmadipour B, Hassanpour H, Rafiei F, Khajali F. Antioxidative, antihyperlipidemic, and growth-promoting effects of kelussia odoratissima in meat-type chickens. Poult Sci. 2015;1(1):37-46.

42. Pesti GM, Combs GF Jr. Studies on the enteric absorption of selenium in the chick using localized coccidial infections. Poult Sci. 1976;55(6):2265-74.

43. Dalia AM, Loh TC, Sazili AQ, Jahromi MF, Samsudin AA. The effect of dietary bacterial organic selenium on growth performance, antioxidant capacity, and Selenoproteins gene expression in broiler chickens. BMC Vet Res. 2017. doi:https://doi.org/10.1186/s12917-017-1159-4.

44. Zhang B, Zhou K, Zhang J, Chen Q, Liu G, Shang N, et al. Accumulation and species distribution of selenium in Se-enriched bacterial cells of the Bifidobacterium animalis 01. Food Chem. 2009;115(2):727-34.

45. Wang WX, Fisher NS. Assimilation efficiencies of chemical contaminants in aquatic invertebrates: A synthesis. Environ Toxicol Chem. 1999. https://doi. org/10.1002/etc.5620180923.

46. Choe DW, Loh TC, Foo HL, Hair-Bejo M, Awis QS. Egg production, faecal pH and microbial population, small intestine morphology, and plasma and yolk cholesterol in laying hens given liquid metabolites produced by Lactobacillus plantarum strains. Br Poult Sci. 2012. doi:https://doi.org/10. 1080/00071668.2012659653.

47. Touchette KJ, Carroll JA, Allee GL, Matteri RL, Dyer CJ, Beausang LA, Zannelli ME. Effect of spray-dried plasma and lipopolysaccharide exposure on weaned pigs: I. Effects on the immune axis of weaned pigs. J Anim Sci. 2002:80(2):494-501.

48. SAS software. version 9.2. NC: SAS Institute Cary; 1996.

\section{Publisher's Note}

Springer Nature remains neutral with regard to jurisdictional claims in published maps and institutional affiliations.

Ready to submit your research? Choose BMC and benefit from:

- fast, convenient online submission

- thorough peer review by experienced researchers in your field

- rapid publication on acceptance

- support for research data, including large and complex data types

- gold Open Access which fosters wider collaboration and increased citations

- maximum visibility for your research: over $100 \mathrm{M}$ website views per year

At $\mathrm{BMC}$, research is always in progress.

Learn more biomedcentral.com/submission 